\title{
Decent work in the Economy for the Common Good reports: a documentary analysis
}

Susana Alves_Pereira ${ }_{\llcorner}$Nuno Rebelo_dos

Santos LLeonor_Pais $S_{\llcorner}$Salvatore_Zappalà

Qualitative Research in Organizations and Management

ISSN: 1746-5648

Article publication date: 7 January 2021

Reprints \& Permissions

Issue publication date: 23 February 2021

\section{Abstract}

\section{Purpose}

This paper aims to describe and characterise the actions carried out by Italian organisations participating in the Economy for the Common Good (ECG) movement and to analyse these actions through the lens of decent work (DW), identifying patterns leading to a typology and conceptual propositions on the subject.

Design/methodology/approach

A documentary analysis was conducted on 14 reports describing the actions taken by Italian organisations that belong to the ECG movement. Qualitative content analysis was performed using QSRNVivo12. The descriptive analysis of the codes was made, as well as a cluster analysis based on coding similarity.

Findings

A total of 1,497 actions were coded, and four clusters, grouping sets of the common good reports, were identified. Results suggest that Customers, Business Partners and Staff and Owners are the most addressed stakeholders, human dignity and environmental sustainability are the most addressed values and Fulfilling and Productive Work and Fundamental Principles and Values at Work are the most addressed DW dimensions. Additionally, all clusters are intensive in environmental concerns but have differentiated 
priorities. Cluster analysis suggests three drivers: recognition, core business closeness and social common good impact. A total of five conceptual propositions are being made useable by organisational leaders who intend to adhere to the ECG movement.

Research limitations/implications

The main limitation is the low number of organisations participating in the ECG movement in Italy, which restricts the scope of the conclusions.

Practical implications

The results are helpful as inputs for designing interventions in organisations that intend to start or strengthen their involvement in the ECG movement.

Originality/value Identifying DW aspects related to common good indicators and the four approaches to the ECG adhesion corresponding to the four clusters.

\section{Keywords}

Documentary analysis; Common good; Values; Decent work

\section{Acknowledgements}

The authors gratefully acknowledge the financial support of "Fundação para a Ciência e Tecnologia" (FCT - Portugal), through the Ph.D. Grant SFRH/BD/130894/2017.Authors contributed equally and significantly to the study and there is no conflict of interest.

\section{Citation}

Pereira, S.A., dos Santos, N.R., Pais, L. and Zappalà, S. (2021), "Decent work in the Economy for the Common Good reports: a documentary analysis", Qualitative Research in Organizations and Management, Vol. 16 No. 1, pp. 191-217. https://doi.org/10.1108/QROM02-2020-1896 


\section{Publisher}

:

Emerald Publishing Limited

Copyright (c) 2020, Emerald Publishing Limited 